Running head: EFFECTS OF AGE ON INVOLUNTARY AND VOLUNTARY

MEMORY

Differential Effects of Age on Involuntary and Voluntary Autobiographical Memory

\author{
Simone Schlagman ${ }^{1}$, Matthias Kliegel ${ }^{2}$, Jörg Schulz ${ }^{1} \&$ Lia Kvavilashvili ${ }^{1}$ \\ ${ }^{1}$ School of Psychology, University of Hertfordshire, UK \\ ${ }^{2}$ Department of Psychology, Technische Universität Dresden, Germany
}

Keywords: Autobiographical memory, involuntary memory, voluntary memory, positivity effect, reminiscence bump, aging

Address for correspondence:

Lia Kvavilashvili

School of Psychology

University of Hertfordshire

Hatfield

College Lane

Hatfield, Herts, AL10 9AB

United Kingdom

Tel. +44 (0) 1707285121

Fax +44 (0) 1707285073

Email: L.Kvavilashvili@herts.ac.uk 


\begin{abstract}
Research of aging and autobiographical memory has almost exclusively focused on voluntary autobiographical memory. However, in everyday life autobiographical memories often come to mind spontaneously without deliberate attempt to retrieve anything. The present study used diary and word-cue methods to compare the involuntary and voluntary memories of 44 young and 38 older adults. The results showed that older adults reported fewer involuntary and voluntary memories than younger adults. Additionally, the life span distribution of involuntary and voluntary memories did not differ in either young (a clear recency effect) or older adults (a recency effect and a reminiscence bump). Despite these similarities between involuntary and voluntary memories, there were also important differences in terms of the effects of age on some memory characteristics. Thus, older adults' voluntary memories were less specific and were recalled slower than those of young adults, but there were no reliable age differences in the specificity of involuntary memories. Moreover, older adults' rated their involuntary memories as more positive than young adults but this positivity effect was not found for voluntary memories. Theoretical implications of these findings for research on autobiographical memory and cognitive aging are discussed.
\end{abstract}


Differential effects of age on involuntary and voluntary autobiographical memories Autobiographical memories are memories of events from one's own personal past and are crucial for developing and maintaining personal identity across the lifespan (Brewer, 1986; Conway \& Pleydell-Pierce, 2000; Rubin, 1986). They are distinguished from autobiographical facts, which refer to autobiographical knowledge without remembering any particular episode (e.g., knowing that Mr. Smith was your primary school teacher), and can vary along several dimensions such as specificity, vividness, perspective, etc. Autobiographical memories can also differ in terms of whether they are recalled deliberately or spontaneously, hence the distinction between voluntary and involuntary autobiographical memory (Ball, 2007; Berntsen, 1996; 1998; Mace, 2007; Schlagman \& Kvavilashvili, 2008).

While research on voluntary autobiographical memory is long-standing with a growing number of studies on older adults, there is only one diary study, published in two parts, on the effects of age on involuntary memories (Schlagman, Schulz \& Kvavilashvili, 2006; Schlagman, Kvavilashvili \& Schulz, 2007). ${ }^{1}$ Moreover, several findings from this study did not replicate the results from research on voluntary autobiographical memories, indicating that age effects obtained on voluntary autobiographical memories cannot be automatically generalised to involuntary memories. The aim of the present study is to fill this gap in research by further examining the effects of age on involuntary autobiographical memory and - for the first time - to directly compare voluntary and involuntary autobiographical memory in young and older adults. The primary focus was on those variables that have been fairly well investigated for voluntary autobiographical memories such as the specificity of memories, their emotional valence (pleasantness), and the distribution of memories across the life span. 


\section{Conceptual rationale of the study}

One consistent pattern of results in cognitive aging research concerns robust age related decrements in laboratory tasks of explicit memory (e.g., free recall, cued recall) but small or no age effects in tasks of implicit memory (e.g., priming, word fragment completion) (Grady \& Craik, 2000; Light et al., 2000; Zacks, Hasher, \& Lee, 2000). This is explained by differential involvement of effortful vs. automatic processes in these tasks. While in the former retrieval is mediated by resource demanding strategic processes, in the latter it is mediated by non conscious automatic processes that do not require one to mentally travel back to an encoding episode (Tulving, 2002).

An important challenge for cognitive aging research is to identify and investigate the nature of those explicit memory tasks that do involve conscious recollection of the past episode but nevertheless are mediated by automatic processes and hence produce minimal or no age effects. There are at least two classes of explicit memory tasks that may fall into this category. One is prospective memory, which involves a conscious recollection of intended action at an appropriate moment (e.g., making a phone call at 2:00 pm) and another is involuntary autobiographical memory (cf. Ball, 2007). While there is an ongoing debate about the extent to which prospective memory is mediated by automatic processes (see Kliegel, McDaniel, \& Einstein, 2008), there seems to be a unanimous agreement about the spontaneous nature of involuntary autobiographical memories (Berntsen, 1996; 2007; Mace, 2007; Mandler, 1994; 2007; Linton, 1986). Thus, at the time of retrieval, people are usually engaged in some fairly mundane activity when, all of a sudden, a memory of a past event pops to mind, often, in response to some cue in the environment or their thoughts (e.g., Berntsen, 1996; Kvavilashvili \& Mandler, 2004). Because there is no 
previous intent or decision to recall a memory, involuntary autobiographical memories, by definition, are not mediated by strategic retrieval processes. This makes them ideally suited for studying the effects of age on automatic processes in explicit memory tasks. Of particular conceptual importance is to compare involuntary and voluntary autobiographical memories to see if the pattern of differential age effects is similar to findings obtained in laboratory tasks of implicit and explicit memory. Effects of age on voluntary autobiographical memories

Despite the prevalence of involuntary memories in everyday life, research on autobiographical memory has almost exclusively concentrated on voluntary memories that are deliberately retrieved in response to specific cues provided by the experimenter (the so called word-cue method; see Rubin, 2005). This research has been instrumental in addressing a variety of theoretical issues such as the nature and organisation of autobiographical memories, their functions and accuracy (e.g., Bluck, 2003; Brewer, 1988; Conway \& Bekerian, 1987; Haque \& Conway, 2001). According to Conway and Playdell-Pearce (2000), autobiographical memory contains information that varies in specificity and has a hierarchical structure with abstract knowledge about life-time periods (e.g., when I lived in London) at the top and specific details of a particular event (e.g., meeting Sarah on the bus for the first time) at the bottom. General memories of repetitive events (e.g., travelling to work every morning) or extended events that lasted longer than a day (e.g., Christmas break in Devon) are in the middle and represent the preferred level of specificity as people often recall general memories even when asked to recall specific memories (Barsalou, 1988; Williams \& Dritschel, 1992; Linton, 1986). Most importantly, specific memories are not stored as whole memories but are constructed by combining sensory information of specific events such as images, feelings, actions etc. with knowledge 
from higher levels of the hierarchy (i.e., general events and life time periods) to form detailed and specific memories. Several lines of research support this model including recent neuroimaging studies (Cabeza \& St. Jacques, 2007), and findings that the deliberate retrieval of autobiographical memories is a slow and effortful process that can take, on average, up to 10 seconds (Conway, 1990; Conway \& Rubin, 1993).

Further evidence in support of the model comes from research on aging and autobiographical memory. Thus, older adults take significantly longer to retrieve autobiographical memories in response to word-cues than younger adults (Dijkstra \& Kaup, 2005; Rubin, \& Schulkind, 1997a; 1997b). In addition, their autobiographical memories lack specific sensory and contextual details and, in comparison to young adults, they are more likely to recall general than specific events from their past (Anderson, Cohen \& Taylor, 2000; Levine, Svobada, Hay, Winocur, \& Moscovitch, 2002; Piolino, Desgranges, Benali, \& Eustache, 2002; Piolino, et al., 2006). Furthermore, Cohen and Faulkner (1988) found that the specificity of older adults' voluntary memories was related to the number of times these memories had been previously recalled (i.e., rehearsed), and argued that frequent rehearsal might be a necessary prerequisite to preserve specific memories in old age. If these memories are not deliberately retrieved on a regular basis the connections deteriorate and the details are lost (Cohen, 1998; Cohen \& Faulkner, 1988; Rabbit \& Winthorpe, 1988).

Despite these difficulties, the recall of voluntary memories is important in old age as it may aid emotional regulation and the maintenance of a positive self-concept (e.g., Fernandes, Ross, Wiegand \& Schryer, 2008; Pasupathi\& Carstensen, 2003). For example, several longitudinal studies have shown that evaluations of past events become more positive with age (e.g., Field, 1982, Kennedy et al., 2004; Levine \& Bluck, 1997), and in some cross-sectional studies older adults have rated their 
voluntary memories as more pleasant than younger adults (e.g., Dijkstra \& Kaup, 2005; Rubin \& Schulkind, 1997a). These findings are important for research in cognitive aging, especially for the Socioemotional Selectivity Theory (see Carstensen, Isaacowitz, \& Charles, 1999; Mather \& Carstensen, 2005), which explains increased positivity in old age by robust motivational shifts in response to a realization that time is running out. This makes older adults focus on positive and ignore negative information in search of emotional meaning and satisfaction.

Another set of important findings in this context concerns the distribution of memories across the lifespan. Thus, regardless of age, people tend to recall recent memories more often than older memories (Rubin, 1999; 2000; Janssen, Chessa, \& Murre, 2005). However, in older adults, in addition to a clear recency effect, there is another (albeit smaller) peak in the recall of memories of events that occurred when participants were approximately between 10-30 years old (Rubin, 1999; 2000). Although the exact age frame of this reminiscence bump varies (e.g., Chu \& Downes, 2000), the phenomenon has been repeatedly reported in the literature and has been found with different retrieval methods including the standard word-cue method, recall of most vivid and important memories as well as life narratives (e.g., Cohen \& Faulkner, 1988; Fitzgerald, 1988; Fitzgerald \& Lawrence, 1984; Fromholt, Mortensen, Torpdahl, Bender, Larsen, \& Rubin, 2003; Rubin \& Schulkind, 1997a; 1997b). However, the ubiquitous nature of reminiscence bump has been recently questioned by a study of Berntsen and Rubin (2002) in which the reminiscence bump was obtained for participants' happiest and most important memories but not for the saddest and most traumatic memories (see also Glück \& Bluck, 2007). Effects of age on involuntary autobiographical memories 
Unlike voluntary memories, very little is known about the effects of age on involuntary autobiographical memories. In an initial diary study by Schlagman et al. (2007), a small group of young and old participants (aged 20-28 and 64-80) recorded their involuntary memories for seven consecutive days. Several novel findings emerged from this study. The first and most important finding was that there was no age effect in the proportion of specific memories (which was equally high in both age groups), and older adults did not report rehearsing their specific memories more frequently than their general memories. Thus, in contrast to voluntary autobiographical memories, older adults appear to have involuntary access to specific memories that have not been maintained by frequent prior rehearsal. Second, older adults showed a clear reminiscence bump with a greatly reduced recency effect. The absence of a recency effect was also reported in an unpublished diary study of Mace (2003) and, according to Schlagman et al. (2007) could be indicative of further differences between voluntary and involuntary autobiographical memories.

Third, Schlagman et al. (2006) examined emotional qualities of involuntary memories and found that older participants rated their memories as more positive than young participants. In addition, a content analysis of memory descriptions showed that while $29 \%$ of young adults' involuntary memories were of typically negative events (e.g., accidents/illnesses, stressful situations and deaths/funerals), only $7 \%$ of older adults' memories fell into these categories. These findings may have important conceptual implications by suggesting that the positivity effect in old age is stronger for involuntary than voluntary memories. Indeed, for voluntary autobiographical memories, a positivity effect has been obtained in some cross-sectional studies (e.g., Dijkstra \& Kaup, 2005; Rubin \& Schulkind, 1997a), but not in others (e.g., Anderson et al., 2000; Fernandes et al. 2008). One possible explanation for these contradictory 
findings is that participants provided only one rating of how pleasant their memory was, and it is not clear whether participants rated the emotional valence of their memories, the original event or a mixture of both. Therefore, in the present study we included pleasantness ratings for both memory (now) and original event (then).

Finally, Schlagman et al. (2007) also showed that, irrespective of age, involuntary memories were reported predominantly in response to some external triggers and during undemanding habitual activities such as walking, washing up, or getting dressed ( $c f$. Berntsen, 1998; Kvavilashvili \& Mandler, 2004). Interestingly, older adults found the execution of these automatic tasks more difficult as they reported higher levels of concentration on these tasks ( $c f$. Kvavilashvili \& Fisher, 2007, Study 2; Lindenberger et al., 2000). This would then leave them with less cognitive capacity to experience additional task unrelated thoughts or memories and, indeed, older adults reported fewer involuntary memories than young adults.

Taken together, results concerning age effects on involuntary autobiographical memories appear to be at odds with research examining voluntary memories both in terms of memory characteristics (e.g., specificity) and their distribution across the lifespan. However, the initial study by Schlagman et al. (2007) has several limitations that question the generalizability and validity of their findings as only 11 young and 10 older adults were tested and no comparison was made with voluntary memories.

\section{Present study: Aims and Hypotheses}

Present study used larger samples of young and old adults who kept a diary of involuntary memories for seven days and recalled voluntary memories with the standard word-cue method. The primary goal was to see if different patterns of aging emerged for voluntary and involuntary memories. From a more general cognitive aging perspective, this is an important comparison as it can shed some light on the 
effects of age on automatic and controlled processes in autobiographical memory and provide evidence for different mechanisms involved in these memories.

Our first aim was to examine several memory characteristics (e.g. specificity, pleasantness, vividness, etc.) as a function of age and memory type. On the basis of previous research, conducted separately on voluntary and involuntary autobiographical memories (see above), it was hypothesized that age by memory type interactions would be obtained for at least two of these characteristics. For example, it was expected that the positivity effect in old age (higher pleasantness ratings) would be stronger for involuntary than voluntary memories. Similarly, for the specificity of memories the prediction was that young and older adults would not differ in the proportion of specific involuntary memories, but that older adults would report reliably fewer specific voluntary memories. We also explored the frequency of prior recall (rehearsal) to assess Cohen and Faulkner's (1988) claim that old adults maintain specific memories only by frequent rehearsal. In this case, one would expect involuntary memories to have higher rates of prior rehearsal than voluntary memories. The second aim was to compare the distribution of voluntary and involuntary memories across the lifespan. For the young group, a clear recency effect was expected for both types of memory (e.g., see Berntsen, 1996; Schlagman et al., 2007). The prediction for the older group was that voluntary memories would exhibit a typical distribution with pronounced recency component and a smaller increase of memories from the reminiscence bump period (10-30 years). An opposite pattern was expected for involuntary memories: a pronounced reminiscence bump with greatly reduced recency effect. The distribution of memories in older adults was also examined for positive, negative and neutral memories to assess a recent claim that the reminiscence bump does not occur for negative memories (Berntsen \& Rubin, 2002). 
Additional predictions concerned the number of involuntary and voluntary memories and retrieval times of voluntary memories. In line with Schlagman et al. (2007), it was expected that older adults would report fewer involuntary memories than young adults (also see Berntsen \& Rubin, 2002). Given their general difficulties with voluntary retrieval (e.g., a lack of specificity), it was also expected that older adults would recall fewer voluntary memories. Significant age effects were predicted also for retrieval times of voluntary memories (Rubin \& Schulkind, 1997a; 1997b).

\section{Method}

\section{Participants}

Thirty-eight older adults (19 males, 19 females) with a mean age of 74.61 years $(S D=3.19$, range $=69-80)$ and 44 psychology undergraduates $(19$ males, 25 females) with a mean age of 21.02 years $(S D=2.41$, range $=18-28)$ took part in the study. The young group participated for course credit. Older adults were community residing and retired, and recruited from a subject pool or by advertising in the local area. They did not report any serious head injury, stroke, or mental health/memory problems diagnosed by a physician. English was the first language of all participants.

Table 1 shows mean scores of background variables as a function of age and the results of several one-way ANOVAs. Older adults were in good health and did not differ from the young in terms their ratings of health in general $(1=$ poor and $5=$ excellent $)$, health in relation to their peers $(1=$ worse, $3=$ same, $5=$ significantly better), and ratings of mood recorded in the diary ( $1=$ very negative, $3=$ neutral, $5=$ very positive). The older group was also cognitively well functioning as indicated by their scores on two sub-tests of the Speed and Capacity of Language-Processing test (SCOLP; Baddeley, Emslie \& Nimmo-Smith, 1992). They had reliably higher scores on the Language Capacity Test (i.e., Spot-the-Word Test), and there were no age 
differences on the Speed of Comprehension Test. However, older adults had spent less time in education and scored lower on a simple free recall task than young adults. Materials and procedure

Initial (screening) telephone interviews were conducted to assess participants' health status and to obtain background information. The researcher also administered a free recall test by reading out ten words (cabin, pipe, elephant, chest, silk, theatre, watch, whip, pillow and giant) and participants had to recall as many words as they could, in any order. Participants were informed that they were taking part in a research project on aging and cognition and were invited to attend two 1-hour experimental sessions eight days apart, and keep a diary of their everyday memory processes in between the two sessions. All participants were tested individually in a quiet room either at the university (mainly young adults) or at their home (mainly old adults).

Session 1 and instructions for the diary. In this session, participants received detailed instructions about the nature of involuntary autobiographical memories, and were asked to record any involuntary memories that occurred during a simple vigilance task (see Schlagman \& Kvavilashvili, 2008 for a detailed description of methodology). Performance on this task was part of another study and is reported elsewhere (Schlagman, Kliegel, Schulz \& Kvavilashvili, in preparation). This was followed by the Speed of Comprehension Test (see additional materials below). At the end of the session participants were informed about their next task - recording involuntary memories in a diary for seven consecutive days. The nature of involuntary autobiographical memories was explained again (Appendix 1), and participants received verbal and written instructions about how to keep the diary (Appendix 2). A copy of the instructions was also on the inside cover sheet of the diary. Participants began recording their involuntary memories the next morning. 
Diary phase (involuntary memory recall). Participants carried the diaries with them for a period of seven days and recorded their involuntary autobiographical memories immediately, or as soon as possible, after their occurrence. If they could not complete the recording immediately but later felt they had forgotten key characteristics a space was provided for them to record this in the form of a tally (tick). There were no restrictions on the type (i.e., memories could be specific or general, recent or remote, etc.) or the number of memories recorded each day.

Participants recorded each memory using a two-page questionnaire. On page one, they recorded the time and date when the memory occurred and when the questionnaire was filled out, and rated their mood immediately before the memory ( $1=$ very negative, $3=$ neutral, 5 =very positive). Then, participants had to briefly describe their memory, and to indicate whether or not it was triggered. If the memory was triggered, they indicated if this was in their thoughts or in the environment and also wrote a description of the trigger. Finally, they gave a rating of memory vividness on a 7-point scale (1=very vague, almost no image at all; 7=very vivid, almost like normal vision). On page two, participants had to describe what activity they were involved in at the time they had the memory and rated how much they were concentrating on this activity on a 5 -point scale ( $1=$ not at all; $5=$ fully concentrating). This was followed by further evaluations of memory characteristics such as how unusual or common the remembered event was (1=very common; 5=very unusual), how pleasant or unpleasant was the memory per se and the remembered event at the time it was experienced ( $1=$ very unpleasant; $3=$ neutral; $5=$ very pleasant $)$, and whether the remembered event was general or specific. Participants' also indicated their age in the memory, and how often the memory had been thought of/rehearsed before (1=never; $2=$ =nce or twice; $3=$ a few times; $4=$ several times; $5=$ many times). 
Voluntary memory recall phase. Session 2 took place one week after Session 1, in the same location and at about the same time. After completing the Language Capacity Test of SCOLP, participants took part in a voluntary memory task in which 30 word-cues (10 negative, 10 neutral and 10 positive; see Appendix 3), in size 18 Arial font, were presented in a fixed random order on an iMac laptop with SuperLab software (for more details of the stimuli see Schlagman \& Kvavilashvili, 2008).

Participants were told that they should deliberately recall an autobiographical memory associated to each of the 30 word-cues presented. Each word cue would stay on the screen for one minute and they had to recall a memory as quickly as possible. If they were unable to do so, the computer would automatically move to the next word-cue. It was also reiterated that past memories could be general or specific in nature and very recent or remote. As soon as participants retrieved a memory they had to click the mouse to pause the computer program and complete the first page of the same autobiographical memory questionnaire used in the diary phase (questions about triggers, ongoing activity and concentration rating were omitted). Once all word-cues were presented participants completed page two of the questionnaire for each memory (i.e., questions on pleasantness, rehearsal, unusualness, specificity, age of memory). Additional measures of cognitive functioning. The Speed of Comprehension Test was taken from SCOLP (Baddeley et al., 1992), and consisted of 100 sentences. Participants were given two minutes to decide whether each sentence was true or false e.g., "Haddocks are fish" and "Desks wear clothes". Performance was measured by the number of correct true/false judgements out of 100 .

The Spot-the-Word Test from the SCOLP measures verbal crystallised intelligence (Baddeley, Emslie, \& Nimmo-Smith, 1993), and consists of 60 pairs of words such as "plorinum-levity" or "thrash-listid". Participants had to indicate which 
of the two was a real word as accurately as possible with no time limit. Performance was measured by the number of correctly rated word pairs out of 60 .

\section{Coding of autobiographical memories}

Before conducting any analyses, two independent raters coded each memory as autobiographical or non-autobiographical (for details see Schlagman et al., 2006; 2007). Inter-rater reliability, calculated for each memory type and age group, was high and ranged from Kappa=.64 ( $S E=.05)$ to Kappa=.84 (SE=.06). Involuntary memories were discarded either because they were deliberately recalled in response to a question (e.g., do you remember when we went to Camden?) or because they were not autobiographical and were examples of current thoughts (thought about having my own personal house), contents of general knowledge (Monica from 'Friends'! One particular episode where she cooks thanksgiving dinner), prospective memory (I remembered I needed to renew a library book), or tip-of-the-tongue state (suddenly the surname popped into my head - I had been trying for weeks to remember). Voluntary memories were discarded because they were either referring to general knowledge or autobiographical facts in the form of general statements without recalling any contextual details (e.g., can't read my wife's handwriting; we are lucky to have a warm fire; always proud of my lovely family and their achievements). Total numbers of discarded and valid autobiographical memories are presented in Table 2. Although more memories were discarded for older adults, this age effect was much stronger for voluntary memories $\left(\chi^{2}[1]=82.38, \mathrm{p}<.00001\right)$ than for involuntary memories $\left(\chi^{2}[1]=3.83, \mathrm{p}=.05\right)$.

\section{Results}

Although all participants made at least one entry in their diary, two old participants, with only one memory each, had to be excluded because their memories 
were discarded as not autobiographical. Therefore, the analyses involving involuntary memories are based on the data of 36 older adults. In line with previous research in this area, the majority of analysis involved using aggregated data (Berntsen \& Hall, 2004; Schlagman \& Kvavilashvili, 2008). For each participant, we calculated means (e.g., mean vividness or rehearsal rating) that were then entered into the ANOVA. When the data were dichotomous (i.e., specific vs. general), mean proportions of specific memories were calculated for each participant and then entered into the analysis in the same fashion. The rejection level was set at .05 and the effect size was measured by partial eta-squared $\left(\eta^{2}\right)$ with small, medium and large effects defined as $.01, .06$ and .16 , respectively (Cohen, 1977).

\section{Number of Memories}

The mean number of involuntary and voluntary memories as a function of age are presented in Table 3 along with the relevant one-way ANOVA results. Older adults recalled reliably fewer voluntary memories $(M=18.89)$ than the young group $(M=24.20){ }^{2}$ In addition, their mean retrieval times were significantly longer $(M=15.20 \mathrm{sec} ; S D=7.95)$ than for younger adults $(M=9.82 \mathrm{sec}, S D=4.38)$, $F(1,80)=14.94, p<.0003, \eta^{2}=.16$.

Results for involuntary memories show that there were no age effects in the mean number of involuntary memories recorded in full. However, older adults had reliably fewer unrecorded memories (in the form of ticks) than young adults ( $M=1.42$ and $M=7.16$, respectively). A significant age effect also emerged for the total number of memories (recorded plus ticked memories). It appears that older adults recorded most of their involuntary memories that they had in full, while younger adults had many more memories than they were able to record (see also Schlagman et al., 2007). 
Triggers. Participants recorded whether or not each involuntary memory was triggered and, if so, whether the trigger was internal or external. Although the majority of memories were reported to have been triggered by external cues $(60 \%)$ compared to internal cues $(23 \%)$ or no triggers $(17 \%)$, this effect was stronger in older adults $\chi^{2}(2)=35.60, p<.0001$ (see Table 4). Examination of the adjusted residuals (which were $>5.00$ ) showed that in comparison to the young group, older adults were more likely to report external triggers and less likely to report no triggers.

Activities and concentration ratings. The examination of participants' descriptions of activities at the time of having a memory showed that older adults were more likely to report being engaged in habitual automatic tasks, like having a cup of tea, or tidying up ( $61 \%$ vs. $48 \%$, respectively), and less likely to be engaged in attentionally demanding activities, like writing or reading, than young adults (39\% vs. $52 \%$, respectively), $\chi^{2}(1)=12.46, p<.001$. Nevertheless, older adults reported marginally higher levels of concentration on these activities $(M=3.43, S D=.81)$ than the young group $(M=3.09, S D=.80), F(1,78)=3.45, p=.067, \eta^{2}=.04$, indicating that they found these simple everyday tasks somewhat more difficult to perform than young adults.

\section{Testing the Main Hypotheses: Memory Characteristics}

Unless otherwise stated, overall mean ratings for all memory characteristics were entered into a 2 (age: young, old) by 2 (memory type: involuntary, voluntary) mixed ANOVAs with the repeated measures on the last factor (see Table 5).

Specificity and prior rehearsal. For specificity, there was a main effect of memory type $F(1,78)=90.77, p<.00001, \eta^{2}=.54$ with the proportion of specific involuntary memories $(M=.78)$ being greater than that of voluntary memories $(M=.60)$. There was also a main effect of age $F(1,78)=15.25, p<.001, \eta^{2}=.16$. Overall, 
older adults reported fewer specific memories $(M=.63)$ than young adults $(M=.74)$. However, as predicted, there was a significant age group by memory type interaction $F(1,78)=8.67, p=.004, \eta^{2}=.10$. A test of simple main effects showed that while older adults reported fewer specific voluntary memories than the young group $\left(F(1,78)=36.69, p<.00001, \eta^{2}=.32\right)$, no significant age effect was obtained for the proportion of specific involuntary memories $(F=1.63)$.

Examination of prior rehearsal showed a main affect of age $(F(1,78)=11.69$, $\left.p=.001, \eta^{2}=.13\right)$ with older adults reporting higher levels of rehearsal $(M=3.00)$ than young adults $(M=2.52)$. However, there was no main effect of memory type $(\mathrm{F}=1.18)$ or age by memory type interaction $(\mathrm{F}=2.59)$, indicating that old participants did not rehearse their (predominantly specific) involuntary memories more frequently than their (less specific/more general) voluntary memories.

Emotional characteristics of memories. For pleasantness of the memories and the original event, the additional factor of time (now vs. then) was added to the 2 (age) by 2 (memory type) mixed ANOVA. There was a main effect of time $F(1,78)=9.38, p=.003, \eta^{2}=.11$ with pleasantness ratings for memory (now) $(M=3.44)$ being higher compared to the original event (then) $(M=3.15)$. Additionally, there was a main effect of memory type $F(1,78)=12.43, p=.001, \eta^{2}=.14$, indicating that overall involuntary memories were more pleasant than voluntary memories. However, this main effect was qualified by a significant interaction with age $F(1,78)=5.17, p<.03$, $\eta^{2}=.06$ (Figure 1). Tests of the simple main effects showed that regardless of time, older adults rated their involuntary memories as more pleasant $(M=3.62)$ than the young group $(M=3.26)\left(F(1,78)=4.61, p<.04, \eta^{2}=.06\right)$ but there was no difference between young and older adults in terms of pleasantness ratings for voluntary memories ( $M=3.16$ and $M=3.14$, for young and older adults, respectively) $(F<1)$. 
Alternatively, involuntary memories were rated as more pleasant $(M=3.62)$ compared to voluntary memories $(M=3.14)$ by the older group $\left(F(1,78)=15.30, \mathrm{p}<.001, \eta^{2}=.16\right)$ but there was no difference in the young group $(F<1)$. A 3-way interaction was not significant $(F<1) .^{3}$

Other Characteristics. The analyses of the remaining memory characteristics revealed main effects of age for vividness ratings $F(1,78)=6.36, p=.01, \eta^{2}=.075$, unusualness ratings $F(1,78)=6.02, p=.02, \eta^{2}=.07$, and age of memories $F(1,78)=330.62, p<.000001, \eta^{2}=.81$. No other main effects or interactions were significant. Thus, older adults' involuntary and voluntary memories were considerably older $(M=33.56)$ compared to young adults $(M=3.87)$. Moreover, older adults rated both their involuntary and voluntary memories as more vivid and more unusual than the young group (see Table 5).

Testing the Main Hypotheses: The Lifespan Distribution of Memories

The frequency distribution of voluntary and involuntary memories across the lifespan was examined separately for the two age groups. To examine the distribution of memories, the age of each memory was calculated by subtracting the age of the participant in the memory from their current age. This would provide the retention time in years for each memory. If the memory was from the current year, retention time would be zero.

The young group. For the young group, the percentage of involuntary and voluntary memories decreases rapidly with an increase in retention time resulting in a clear recency effect with $29 \%(N=128)$ and $28 \%(N=294)$ of involuntary and voluntary memories, respectively, coming from the most recent year (Figure 2). A curve-fitting regression analysis conducted on the young adults' number of memories separately for each memory type confirmed that the shape of each frequency 
distribution resembled a decay function, the hyperbolic regression model accounted for $98 \%$ of the variance of the observed counts for voluntary memories and $96 \%$ of the variance of the observed counts for involuntary memories.

The old group. The possible age range of older adults' memories was very large and, therefore, the data were examined in decades (eight in total). Initially, the shape of the frequency distribution of memories was investigated as a function of their pleasantness (positive, negative, neutral), to see if negative memories were distributed differently than positive and neutral memories (see Berntsen \& Rubin, 2002). However, there was no statistically reliable association between the eight decades and the type of memory valence either for involuntary memories, $\chi^{2}(14, N=$ $292)=16.7, p=.27$, or for voluntary memories, $\chi^{2}(14, N=684)=15.1, p=.37$ (the corresponding effect size correlations were also very modest, Contingency Coefficient $=.23$ and .15 respectively). Therefore, the frequency distributions were examined irrespective of their valence (see Figure 3). There were similar distributions for both types of memories: a somewhat reduced recency effect and, although slightly smaller than the recency component, a very clear reminiscence bump for the decades of 50-59 and 60-69 years (i.e., when participants were approximately 10-30 years old).

Several log-linear analyses were conducted on this data. First, a model of independence was tested, which predicted that the percentages of memories falling into each of the eight decades would not differ according to type of memory (voluntary vs. involuntary). This model produced an excellent fit, $L R(7)=5.98, p=.54$, indicating that age of memory and type of memory were not associated. Therefore, the frequencies were collapsed across memory type for the further analyses. The next model tested for an equal number of expected cell counts in each of the eight decades but produced a poor fit and was rejected $L R(8)=167.95, p<.001$. Two additional 
models used generalised log-odds contrasts to test for differences between different decades. First, we tested for a difference between the frequencies in the most recent decade and the two decades in the bump period. The model had an excellent fit $L R(2)=.08, p=.96$. Thus, there were significantly more memories from the most recent decade compared to the bump period. Second, we tested whether there was a difference between the frequencies of memories in the bump period and the four decades between the most recent decade and bump period. This model also produced an excellent fit $L R(4)=.44, p=.98$, showing that significantly more memories were in the bump period than the other four decades after the most recent decade. In sum, the age distribution of involuntary and voluntary memories included both a recency effect and a reminiscence bump (see Figure 3).

\section{Discussion}

The primary objective of the present investigation was to compare age effects on explicit (autobiographical) memory tasks which differ only in terms of whether their retrieval is mediated by automatic or strategic processes (involuntary and voluntary autobiographical memories, respectively). It was expected that some of the age by memory task interactions would be similar to those obtained for laboratory tasks of explicit and implicit memory. Several variables were investigated but the primary focus was on memory characteristics such as specificity, pleasantness and the life-span distribution of memories. Below, findings for these and other variables will be discussed together with their theoretical implications followed by methodological considerations and conclusions.

Age effects on specificity, number of memories and retrieval times of voluntary memories

Large age effects obtained in our study for voluntary memories both replicate and extend the previous findings on aging and autobiographical memories. Thus, on 
average, older adults took 15 seconds to retrieve memories (five seconds longer than younger adults). Although these retrieval times appear very long, they are in line with previous studies which show that older adults can take up 13 to 20 seconds to retrieve a memory (e.g., Fitzgerald \& Lawrence, 1984; Rubin \& Schulkind, 1997a; 1997b). Second, older group recalled significantly fewer specific voluntary memories (51\%) than the young group (67\%), a finding which is also well-documented (e.g., Levine et al., 2002; Piolino et al., 2002).

In contrast, old and young adults did not differ in the proportion of specific involuntary autobiographical memories, which was equally high in both age groups (75\% and $80 \%$, respectively). This is particularly surprising because, unlike previous studies on aging and autobiographical memory, our instructions did not request the recall of specific memories only (see Appendix 1). Moreover, the high level of specificity in older adults was not maintained by frequent rehearsal (see Cohen, 1998), as they did not report rehearsing their involuntary memories more often than voluntary memories. Thus, older adults appear to be able to effortlessly access specific details of one-off events but, at the same time, experience considerable difficulties when trying to access these events via deliberate search processes.

In line with Craik's (1986) influential model of memory and aging, this contrasting pattern of findings should be indicative of different mechanisms involved in these two types of memory. According to this model, age effects will be larger for those memory tasks that are primarily mediated by self-initiated controlled processes (e.g., free recall) and smallest or non-existent for tasks mediated by automatic processes (e.g., priming and implicit memory) (see also Grady \& Craik, 2000). It is interesting that both priming and implicit memory tasks involve non-conscious access of past information. The results of the present study are important because they show 
that age effects can also be absent in some explicit memory tasks which do require conscious retrieval and mental time travel to a previous episode.

Currently, there are contradictory conceptual views on how involuntary autobiographical memories are constructed and retrieved. According to Conway (2005), involuntary memories are directly retrieved from a separate pool of very recent memories that are not yet consolidated into the autobiographical memory system (see also Berntsen, 1998). In contrast, Schlagman and Kvavilashvili (2008) have suggested that involuntary autobiographical memories are retrieved (and constructed) from the same autobiographical system as voluntary memories. The only difference between the voluntary and involuntary memories lies in the nature of the retrieval process. In the former, one consciously directs the search process through the hierarchy (e.g., see Haque \& Conway, 2001), ${ }^{4}$ while in the latter, an incidental cue (internal or external) spontaneously activates the representation of this cue, which then spreads automatically through the autobiographical memory system. If there is a perfect match between key features of the representation of this cue and some already activated fragments of previous event(s) at the bottom of the hierarchy, a specific autobiographical memory is formed and automatically delivered to consciousness.

Initial support for this model comes from the studies of Schlagman and Kvavilashvili (2008) on young adults which showed that involuntary memories were more specific and were recalled significantly faster than voluntary memories. Present findings concerning the absence of an age effect in the specificity of involuntary memories provide additional support for the idea that these memories are accessed automatically from the bottom of the autobiographical memory system. Of particular importance is the finding that (predominantly specific) involuntary memories recalled by older adults were not of very recent events, as proposed by Conway (2005). In 
fact, the average age of involuntary memories was 35.69 years and was not reliably different from that of voluntary memories (i.e., 31.45 years).

Effects of age on the pleasantness of memories

The second set of important findings concerns a significant age by memory type interaction for pleasantness ratings of autobiographical memories. In line with our predictions, older adults rated their involuntary memories as more pleasant than younger adults. It is important that this finding was not due to a mood congruency effect as older adults did not rate their mood as more positive than young adults at the time involuntary memory occurred (see Table 1), and the correlations between the ratings of mood and emotional valence of memories were fairly modest in size in both young $(r(439)=.34, p<.0001)$ and older adults $(r(299)=.28, p<.0001)$.

In contrast, older adults' ratings of voluntary memories were not more positive than those of younger adults (for similar results see Anderson et al., 2000; Fernandes, Ross, Wiegand, \& Schryer, 2008). Also, there was no positivity effect for the number of voluntary memories as a function of cue valence as equal numbers of memories were recalled to positive, negative and neutral cues (see footnote 2). Moreover, when we examined participants' pleasantness ratings as a function of cue valence (positive, negative, neutral), there were no age effects in the ratings of memories for positive and neutral cues, but older adults' ratings of memories to negative cues were reliably more negative than younger adults (see footnote 3 ). Taken together, our findings do not demonstrate the positivity effect for voluntary autobiographical memories, at least with the word-cue method used here. However, we found a clear positivity effect for involuntary memories.

This contrasting pattern raises some important theoretical and methodological issues for research on the positivity effect and the Socioemotional Selectivity Theory. 
Research in this area has often been conducted on non-autobiographical material such as words, images, faces (Mather \& Carstensen, 2005), and recent findings have shown that the positivity effect is mediated by strategic rather than automatic processes. For example, in a study by Rösler and colleagues (2005), both older and younger adults' attention was initially captured by negative emotional scenes, but older adults chose to disengage their attention from them, while this tendency was not present in younger adults. Moreover, in a study by Mather and Knight (2005, Experiment 3) older adults recalled a smaller proportion of negative pictures than young adults in a full attention condition, but this effect disappeared (was even reversed) under a divided attention condition. It appears that older adults strategically diverted their attention away from negative stimuli, but this process was disrupted in a divided attention condition.

However, the results of the present study suggest that the positivity effect is not always due to strategic processes. In case of involuntary autobiographical memories it is clearly mediated by automatic processes because the occurrence of involuntary memories is not under our conscious control, they simply pop into mind unexpectedly (e.g., see Mandler, 2007). This is a novel finding that needs to be studied in more detail in the future. One possibility is that the positivity effect for involuntary memories occurs because older adults deliberately divert their attention from potentially negative stimuli/triggers, which will prevent them experiencing negative involuntary memories. However, initial findings from a laboratory task of involuntary memories showed that older adults did not report fewer involuntary memories in response to negative cues than young participants (see Schlagman, et al., in preparation). Clearly, more research needs to be conducted on this issue in the future. It is also important to compare positivity effect across various memory tasks 
(i.e., involuntary/voluntary autobiographical memory and laboratory tasks of recall and recognition of words, images, etc) in a single sample to examine possible reasons for discrepant patterns of findings (e.g., see Fernandes, et al., 2008).

\section{Distribution of involuntary and voluntary memories across the life span}

The third research question of this study concerned the lifespan distribution of involuntary and voluntary autobiographical memories. For the young group, the distribution of involuntary and voluntary memories was identical (see Figure 2). Most memories were retrieved from the last five years, and the largest number of memories was from the most recent year and then the number of memories clearly decreased each year until evening out at about five retention years. This finding replicates previous work examining both involuntary and voluntary autobiographical memory in young participants (e.g., Berntsen, 1998; Rubin, 1999). Importantly, the distributions of the older adults' involuntary and voluntary memories were also identical as they included a clear recency effect and a reminiscence bump falling between the ages of approximately 10-30 years (see Figure 3). These findings are in line with previous studies on voluntary autobiographical memories (see Rubin, 1999) but contradict the results of Schlagman et al. (2007) and Mace (2003) who did not obtain a strong recency effect for involuntary autobiographical memories. A possible reason for this discrepancy is a lack of power in the previous studies due to small samples.

The results of the present study are also important because they showed that the shape of the distribution of memories in older adults (i.e., the recency component and the reminiscence bump) did not depend on the type of memories (positive, negative, neutral). It appears that the absence of a reminiscence bump for negative autobiographical memories found by Berntsen and Rubin (2002) might be due to the particular method whereby participants were specifically asked to recall their most 
negative memories, but not when memories simply pop to mind or when participants have to recall memories in response to word-cues. This issue, however, requires further and more in depth investigation in the future.

\section{Additional findings}

Number of recalled/recorded memories. Older adults recalled reliably fewer voluntary memories in response to the word-cues than young adults. This is a novel finding that provides further support for the idea that deliberate retrieval of autobiographical memories in response to word-cues is a fairly demanding task for older adults. However, there was also a significant age effect in the total number of recalled (recorded plus ticked) involuntary memories. Although this is in line with previous findings on involuntary autobiographical memories (see Berntsen \& Rubin, 2002; Schlagman et al., 2007), it contains an apparent paradox. If involuntary memories are brought about by a process of spreading activation that is entirely automatic and non-conscious (see Schlagman \& Kvavilashvili, 2008), why did older adults record fewer involuntary memories than the young adults?

A possible explanation is that although the retrieval of involuntary memories per se is automatic and does not require attentional resources, its end product (i.e., thinking about the contents of involuntary memory) is not. Thus, to think about the contents of an involuntary memory and to process the stimuli as part of an ongoing activity requires some spare working memory capacity. Since older adults may need to pay more attention to the execution of fairly automatic activities, as shown by the results of the present study (see also Kvavilashvili \& Fisher, 2007; Schlagman et al., 2007) they will have less working memory resources available to become aware of and process task-unrelated thoughts and memories that may be automatically activated by incidental stimuli (see also Kvavilashvili \& Mandler, 2004). An 
alternative but not mutually exclusive possibility is that because they have to concentrate so much on the ongoing activity they are less likely to notice the available cues in the environment.

Other memory characteristics. In addition to specificity and pleasantness, significant effects of age were obtained for several other memory characteristics. Unsurprisingly, older adults' memories (both voluntary and involuntary) were older than memories of young adults. Their memories were also more rehearsed simply because they would have had more opportunities (or years) to think about their memories than young adults. Older adults also rated their involuntary and voluntary memories as more vivid and unusual than young adults. Although this finding was unexpected, it is in line with several other studies of voluntary autobiographical memories which also showed higher vividness ratings in older adults (Cohen \& Faulkner, 1988; Comblain, et al., 2005; Rubin \& Schulkind, 1997a). It appears that the increased vividness of older adults' autobiographical memories may be a general phenomenon and worthy of more in depth examination.

\section{Methodological issues}

During the initial coding of voluntary and involuntary autobiographical memories approximately $12 \%$ of older adults' memories had to be discarded because they were not autobiographical in nature. It is unlikely that this happened because older participants did not understand instructions and/or the concept of involuntary or voluntary autobiographical memories as explanations were sufficiently detailed (see Appendix 1 and 2). A relatively large number of non-autobiographical voluntary memories $(\mathrm{N}=107)$ may reflect older adults' tendency to report general autobiographical facts and/or irrelevant, non-autobiographical information when asked to recall or reminisce about their past (see St. Jaques \& Levine, 2007). Indeed, 
$71 \%(\mathrm{~N}=76)$ of their discarded voluntary memories referred to general autobiographical facts without any reference to contextual details or events that happened at a particular time and place (see method section). ${ }^{5}$ Had we retained these memories, the age decrement in the specificity of voluntary memories would have been even stronger than currently reported. It is also important that there was almost no overlap in the contents of voluntary and involuntary memories, indicating that involuntary memories recorded in a diary did not affect participants' voluntary recall of memories in Session 2.

Another methodological issue concerns the finding that older adults' memories were significantly older than young adults' memories. This raises a possibility that age effects obtained in the present study were due to increased age of memories in older adults rather than group differences in chronological age. If this was the case then there should be reliable positive correlations between the age of memories and memory characteristics in the group of older adults, especially for involuntary memories (i.e., older memories should be more specific, pleasant, vivid, etc.). However, most of these correlations were non-significant. If anything, small negative correlations were obtained for the vividness of involuntary $(r(291)=-.17$, $p=.003)$ and voluntary $(r(689)=-.19, p<.0001)$ memories, indicating that older adults' recent memories were more vivid than older memories. A reliable positive correlation was obtained only for the rehearsal rating of involuntary memories $(r(291)=.23$, $p<.0001)$ indicating that older adults' older memories were more rehearsed than recent memories. These results indicate that pattern of findings obtained in the present study is unlikely to be caused by group differences in age of memories.

\section{Conclusions}


The results of the present study show that age affects some characteristics of involuntary and voluntary autobiographical memories similarly, for example, the number of memories reported and the distribution of memories across the lifespan. On the other hand, differential effects of age on involuntary and voluntary memories were obtained for the specificity of memories and the positivity effect. These findings have important implications for current theories of autobiographical memory and the Socioemotional Selectivity Theory, respectively. They also emphasise the necessity of distinguishing between involuntary and voluntary autobiographical memory and show that examining the effects of age can further enrich the research on memory and aging as well as provide important insights into the nature and functions of involuntary autobiographical memory. 


\section{References}

Anderson, S. J., Cohen, G., \& Taylor, S. (2000). Rewriting the past: some factors affecting the variability of personal memories. Applied Cognitive Psychology, 14, 435-454.

Baddeley, A., Emslie, H., \& Nimmo-Smith, I. (1992). The speed and capacity of language-processing test. Bury St. Edmunds: Thames Valley Test Company.

Baddeley, A., Emslie, H., \& Nimmo-Smith, I. (1993). The spot-the-word test: A robust estimate of verbal intelligence based on lexical decision. British Journal of Psychology, 32, 5565.

Ball, C. T. (2007). Can we elicit involuntary autobiographical memories in the laboratory? In J. H. Mace (Ed.), Involuntary memory (pp. 127-152). Malden, USA: Blackwell Publishing.

Barsalou, L. W. (1988). The content and organisation of autobiographical memories. In U. Neisser, \& W. Winograd (Eds.). Remembering reconsidered: ecological and traditional approaches to the study of memory (pp. 193-243). Cambridge: Cambridge University Press.

Berntsen, D. (1996). Involuntary autobiographical memories. Applied Cognitive Psychology, 10, 455-460.

Berntsen, D. (1998). Voluntary and involuntary access to autobiographical memory. Memory, 6, 113-141.

Berntsen, D. (2007). Involuntary autobiographical memories: Speculations, findings, and an attempt to integrate them. In J. H. Mace (Ed.), Involuntary memory (pp. 1-19). Malden, USA: Blackwell Publishing.

Berntsen, D. \& Hall, N. M. (2004). The episodic nature of involuntary autobiographical memories. Memory \& Cognition, 32, 789-803.

Berntsen, D. \& Rubin, D. C. (2002). Emotionally charged autobiographical memories across the life span: The recall of happy, sad, traumatic and involuntary memories. Psychology 
and Aging, 17, 636-652.

Bluck, S. (2003). Autobiographical memory: exploring its functions in everyday life. Memory, 11, 113-123.

Brewer, W. F. (1986). What is autobiographical memory? In D. C. Rubin (Ed.), Autobiographical memory (pp. 25-49). Cambridge: Cambridge University Press.

Brewer, W. F. (1988). Memory for randomly sampled autobiographical events. In U. Neisser, \& W. Winograd (Eds.). Remembering reconsidered: ecological and traditional approaches to the study of memory (pp. 21-30). Cambridge: Cambridge University Press.

Cabeza, R., \& St. Jacques, P. (2007). Functional neuroimaging of autobiographical memory. Trends in Cognitive Sciences, 11, 219-227.

Carstensen, L. L., Isaacowitz, D. M., \& Charles, S. T. (1999). Taking time seriously: A theory of socioemotional selectivity. American Psychologist, 54, 165-181.

Chu, S. \& Downes, J. J. (2000). Odor-evoked autobiographical memories: Psychological investigations of Proustian phenomena. Chemical Senses, 25, 111-116.

Cohen, J. (1977). Statistical power analysis for the behavioral sciences. New York: Academic Press.

Cohen, G. (1998). The effects of ageing on autobiographical memory. In C. P. Thompson, D. J. Herrman, D. Bruce, J. G. Payne, \& M. P. Toglia (Eds.). Autobiographical memory, theoretical and applied perspectives (pp. 105-123). London: Lawrence Erlbaum Associates.

Cohen, G., \& Faulkner, D. (1988). Lifespan changes in autobiographical memory. In M. M. Gruneberg, P. E. Morris, \& R. N. Sykes (Eds.), Practical aspects of memory: Current research and issues (Vol. 1, pp. 277-282). Chichester, UK: Wiley.

Conway, M. A. (1990). Autobiographical memory: an introduction. Milton Keynes: Open University Press. 
Conway, M. A. (2005). Memory and the self. Journal of Memory and Language, 53, 597-628.

Conway, M. A. \& Bekerian, D. A. (1987). Organization in autobiographical memory. Memory and Cognition, 15, 119-132.

Conway, M. A. \& Pleydell-Pearce, C. W. (2000). The construction of autobiographical memories in the self memory system. Psychological Review, 107, 261-288.

Conway, M. A. \& Rubin, D. C. (1993). The structure of autobiographical memory. In A. E. Collins, S. E. Gathercole, M. A. Conway, \& P. E. Morris (Eds.), Theories of memory (pp. 103-138). Hove, Sussex: Lawrence Erlbaum Associates.

Comblain, C., D’Argembeau, A., \& Van der Linden, M. (2005). Phenomenal characteristics of autobiographical memories for emotional and neutral events in older and younger adults. Experimental Aging Research, 31, 173-189.

Craik, F. I. M. (1986). A functional account of age differences in memory. In F. Clix, \& H. Hagendorf (Eds.), Human memory and cognitive capabilities: Mechanisms and performances (pp. 409-422). Amsterdam: Elsevier.

Dijkstra, K. \& Kaup, B. (2005). Mechanisms of autobiographical memory retrieval in younger and older adults. Memory \& Cognition, 33, 811-820.

Fernandes, M., Ross, M., Wiegand, M., \& Schryer, E. (2008). Are the memories of older adults positively biased? Psychology and Aging, 23, 297-306.

Field, D. (1981). Retrospective reports by healthy intelligent older people of personal events of their adult lives. International Journal of Behavioural Development, 4, 77-97.

Fitzgerald, J. M. (1988). Vivid memories and the reminiscence phenomenon: The role of a self narrative. Human Development, 31, 261-273.

Fitzgerald, J. M., \& Lawrence, R. (1984). Autobiographical memory across the lifespan. Journal of Gerontology, 39, 692-698. 
Fromholt, P., Mortensen, D. B., Torpdahl, P., Bender, L., Larsen, P., \& Rubin, D. C. (2003). Life-narrative and word-cued autobiographical memories in centenarians: Comparisons with 80-year old control, depressed and dementia groups. Memory, 11, 81-88.

Glück, J. \& Bluck, S. (2007). Looking back across the life span: A life story account of reminiscence bump. Memory and Cognition, 35, 1928-1939.

Grady, C. L., \& Craik, F. I. M. (2000). Changes in memory processing with age. Current Opinion in Neurobiology, 10, 224-231.

Haque, S., \& Conway, M. A. (2001). Sampling the process of autobiographical memory construction. European Journal of Cognitive Psychology, 13, 529-457.

Janssen, S. M. J., Chessa, A. G., \& Murre, J. M. J. (2005). The reminiscence bump in autobiographical memory: Effects of age, gender, education, and culture. Memory, 13, 685-668.

Kennedy, Q., Mather, M., \& Carstensen, L. L. (2004). The role of motivation in the agerelated positivity effect in autobiographical memory. Psychological Science, 15, 208-214.

Kliegel, M., McDaniel, M. A., \& Einstein, G. O. (2008) (Eds.). Prospective memory: Cognitive, neuroscience, developmental, and applied perspectives. New York: Lawrence Erlbaum Associates.

Kvavilashvili, L., \& Fisher, L. (2007). Is time-based prospective remembering mediated by self-initiated rehearsals?: Role of cues, ongoing activity, age and motivation. Journal of Experimental Psychology: General, 136, 112-132.

Kvavilashvili, L. \& Mandler, G. (2004). Out of one's mind: A study of involuntary semantic memories. Cognitive Psychology, 48, 47-94.

Levine, L. J. \& Bluck, S. (1997). Experienced and remembered emotional intensity in older adults. Psychology \& Aging, 12, 514-523.

Levine, B., Svoboda, E., Hay, J. F., Winocur, G., \& Moscovitch, M. (2002). Aging and autobiographical memory: Dissociating episodic from semantic retrieval. Psychology and 
Aging, 17, 677-689.

Light, L., Prull, M. W., La Voie, D. J., \& Healy, M. (2000). Dual process theories of memory in old age. In T. J. Perfect and E. A. Maylor (Eds.), Models of cognitive aging (pp. 238-300). Oxford: Oxford University Press.

Lindenberger, U., Marsiske, M., \& Baltes, P. B. (2000). Memorizing while walking: Increase in dual-task costs for young adulthood to old age. Psychology and Aging, 15, 417-436.

Linton, M. (1986). Ways of searching and the contents of memory. In D.C. Rubin (Ed.), Autobiographical memory (pp. 50-66). Cambridge: Cambridge University Press.

Mace, J. H. (2003, July). Involuntary autobiographical memory and the reminiscence effect. Paper presented at the $5^{\text {th }}$ Biennial meeting of the Society of Applied Research in Memory and Cognition, University of Aberdeen (Scotland).

Mace, J. H. (2007). Involuntary memory: Concept and theory. In J. H. Mace (Ed.), Involuntary memory (pp. 1-19). Malden, USA: Blackwell Publishing.

Mandler, G. (1994). Hypermnesia, incubation, and mind popping: On remembering without really trying. In C. Umilta, \& M. Moscovitch (Eds.), Attention and performance XV (pp. 3-33). Cambridge, MA: The MIT Press.

Mandler, G. (2007). Involuntary memories: Variations on the unexpected. In J. H. Mace (Ed.), Involuntary memory (pp. 208-223). Malden, USA: Blackwell Publishing.

Mather, M., \& Carstensen, L. L. (2005). Aging and motivated cognition: The positivity effect in attention and memory. Trends in Cognitive Sciences, 9, 496-502.

Mather, M. \& Knight, M. (2005). Goal directed memory: The role of cognitive control in older adults' emotional memory. Psychology and Aging, 20, 554-570.

Pasupathi, M., \& Carstensen, L. L. (2003). Age and emotional experience during mutual reminiscing. Psychology and Aging, 18, 430-442.

Piolino, P., Desgranges, B., Benali, K., \& Eustache, F. (2002). Episodic and semantic 
remote autobiographical memory in aging. Memory, 10, 239-257.

Piolino, P., Desgranges, B., Clarys, D., Guillery-Girard, B., Taconnat, L., Isingrini, M., \& Eustache, F. (2006). Autobiographical memory, autonoetic consciousness, and selfperspective in aging. Psychology and Aging, 21, 510-525.

Rabbit, P., \& Winthorpe, C. (1988). What do old people remember? The Galton paradigm reconsidered. In M. M. Gruneberg, P. E. Morris \& R. N. Sykes (Ed.), Practical aspects of memory: current research and issues (Vol 1, pp. 277-282). Chichester, UK: Wiley.

Rösler, A., Ulrich, C., Billino, J., Sterzer, P., Weidauer, S., Bernhardt, T., et al. (2005). Effects of arousing emotional scenes on the distribution of visuospatial attention: Changes with aging and early sub-cortical vascular dementia. Journal of the Neurological Sciences, 229-230, 109-116.

Rubin, D. C. (1986) (Ed.) Autobiographical memory. Cambridge: Cambridge University Press.

Rubin, D. C. (1999). Autobiographical memory and aging: Distributions of memories across the life-span and their implications for survey research. In D. C. Park \& N. Schwarz (Eds.), Cognition, aging and self-reports (pp. 163-183). Hove, England: Psychology Press.

Rubin, D. C. (2000). Autobiographical memory and aging. In D. Park and N. Schwarz (Eds.), Cognitive aging: A primer (pp. 131-149). Philadelphia, PA: Psychology Press.

Rubin, D. C. (2005). Autobiographical memory tasks in cognitive research. In A. Wenzel \& D. C. Rubin (Eds.), Cognitive methods and their application to clinical research (pp. 219-241). Washington: American Psychological Association.

Rubin, D. C. \& Schulkind, M. D. (1997a). Distribution of important and word-cued autobiographical memories in 20-, 35-, and 70-year old adults. Psychology and Aging, 12, 524535.

Rubin, D. C. \& Schulkind, M. D. (1997b). The distribution of autobiographical 
memories across the lifespan. Memory \& Cognition, 25, 859-866.

Schlagman, S., Kliegel., M., Schulz, J., \& Kvavilashvili, L. (in preparation). Eliciting involuntary autobiographical memories in the laboratory: Examining the effects of age.

Schlagman, S., \& Kvavilashvili, L. (2008). Involuntary autobiographical memories in and outside the laboratory: How different are they from voluntary autobiographical memories? Memory and Cognition, 36, 920-932.

Schlagman, S., Kvavilashvili, L., \& Schulz, J. (2007). Involuntary autobiographical memory and aging. In J. H. Mace (Ed.), Involuntary memory (pp. 87-112). Malden, USA: Blackwell Publishing.

Schlagman, S., Schulz, J., \& Kvavilashvili, L. (2006). A content analysis of involuntary autobiographical memories: Examining the positivity effect in old age. Memory, 17, 161-175.

St. Jacques, P. L., \& Levine, B. (2007). Ageing and autobiographical memory for emotional and neutral events. Memory, 15, 129-144.

Tulving, E. (2002). Episodic memory: From mind to brain. Annual Review of Psychology, 53, 1-25.

Williams, J. M. G. \& Dritschel, B. H. (1992). Categoric and extended autobiographical memories. In M. A. Conway, D. C. Rubin, H. Spinnler, \& W. A. Wagenaar (Eds.), Theoretical perspectives on autobiographical memory (pp. 391-410). Dordrecht, the Netherlands: Kluwer Academic Publishers.

Zacks, R. T., Hasher, L., \& Li, H. (2000). Human Memory. In F. I. M. Craik \& T. A. Salthouse (Eds.), The handbook of aging and cognition (pp. 293-. London: Lawrence Erlbaum Associates. 


\section{Footnotes}

${ }^{1}$ There is also one unpublished diary study by Mace (2003) and a questionnaire study of Berntsen and Rubin (2002) in which participants had to retrospectively recall their most recent involuntary memory that they had experienced in their everyday life.

${ }^{2}$ Importantly, both young and old participants recalled equal numbers of memories in response to positive, negative and neutral cues as shown by a non significant interaction $(\mathrm{F}=2.21)$ obtained in an additional 2 (age group) x 3 (cue valence) mixed ANOVA with the repeated measures on the last factor. In the young group, the number of recalled memories to positive, negative and neutral cues was 8.02 $(S D=2.23), 8.02(S D=2.12)$ and $8.05(S D=2.36)$. In the old group the respective means were $6.50(S D=2.15), 6.50(S D=2.44)$, and $5.79(S D=2.48)$.

${ }^{3}$ An additional analysis was conducted on voluntary memories only by calculating mean emotional valence ratings as a function of cue-type (negative, neutral, positive) and entering these means into a 2 (age group) x 3 (cue-valence: negative, neutral, positive) mixed ANOVA with repeated measures on the last factor. This analysis resulted in the main effect of cue valence $F(2,158)=250.16, p<.000001, \eta^{2}=.76$, with memories retrieved to positive cues being rated significantly higher $(M=4.14, \mathrm{SD}=.50)$ than memories retrieved to neutral cues $(M=3.22, \mathrm{SD}=.53)(p<.000001)$ that, in turn, were rated as more positive than those retrieved to negative cues $(M=2.37)(p<.000001)$. The main effect of age was not significant $(F<1)$, however, there was a reliable age by cue valence interaction $F(2,158)=6.43, p=.002, \eta^{2}=.08$. Tests of simple main effects showed that young and old participants did not differ in their ratings of memories recalled to neutral cues $(M=3.22$ and $M=3.23)(F<1)$ and positive cues $(M=4.05$ and $M=4.25)$ $\left(F(1,79)=3.12, p=.08, \eta^{2}=.04\right)$. However, older adults rated memories to negative cues more negatively $(M=2.17)$ than young adults $(M=2.54)\left(F(1,79)=7.61, p=.007, \eta^{2}=.09\right)$. 
${ }^{4}$ In our study, for example, older adults took significantly longer to direct this search and, in almost $50 \%$ of cases, they terminated it prematurely by recalling general memories instead of specific events.

${ }^{5}$ Only $8 \%$ of younger adults' discarded voluntary memories were autobiographical facts. The majority (21 out of 26) referred to contents of general knowledge. 
Table 1

Mean Scores (Standard Deviations in Brackets) of Background Variables as a Function of Age (young vs. old). See Text for Description of These Measures. Right Hand Columns Present Results of One-Way ANOVAs on Means with Age Group as Independent Variable (F Values and Effect Sizes).

\begin{tabular}{lllll}
\hline & \multicolumn{3}{c}{ Group } & \\
\cline { 2 - 3 } & Young & Old & $F(1,80)$ & Effect Size \\
& $N=44$ & $N=38$ & & (partial $\left.\eta^{2}\right)$ \\
\hline General Health & $3.70(.58)$ & $3.92(.54)$ & 3.01 & 0.036 \\
Health (self vs. peers) & $3.50(.73)$ & $3.79(.74)$ & 3.16 & 0.038 \\
Mood & $3.31(.48)$ & $3.39(.56)$ & .49 & 0.00 \\
SCOLP-Language Capacity & $45.64(5.27)$ & $54.79(8.10)$ & $37.73 * *$ & 0.32 \\
SCOLP- Speed of & $63.45(16.62)$ & $67.45(14.10)$ & 1.54 & 0.02 \\
Comprehension & & & & \\
Immediate Free Recall Test & $5.95(1.14)$ & $5.08(1.56)$ & $8.49 *$ & 0.10 \\
Years in Education & $14.73(1.25)$ & $12.74(3.28)$ & $13.84 * *$ & 0.15 \\
\hline
\end{tabular}

$* p<.05 * * p<.001$ 
Table 2

Number of Valid and Discarded Voluntary and Involuntary Autobiographical Memories as a Function of Age Group (Young vs. Old). Percentages in Brackets.

Autobiographical Memories

\begin{tabular}{lccc}
\hline & Valid & Discarded & Total \\
\hline Voluntary memories & $1065(97 \%)$ & $28(3 \%)$ & $1093(100 \%)$ \\
Young & $718(87 \%)$ & $111(13 \%)$ & $829(100 \%)$ \\
Old & $1783(93 \%)$ & $139(7 \%)$ & $1922(100 \%)$ \\
Total & & & \\
Involuntary memories & $437(93 \%)$ & $33(7 \%)$ & $470(100 \%)$ \\
Young & $301(89 \%)$ & $37(11 \%)$ & $338(100 \%)$ \\
Old & $738(91 \%)$ & $70(9 \%)$ & $808(100 \%)$ \\
Total & & & \\
\hline
\end{tabular}


Table 3

Means, Standard Deviations and Ranges of Valid Voluntary and Involuntary

Memories as a Function of Age Group (Young vs. Old). Right Hand Columns Present

Results of One-Way ANOVAs on Means with Age Group as Independent Variable (F

Values and Effect Sizes).

\begin{tabular}{|c|c|c|c|c|}
\hline & \multicolumn{2}{|c|}{ Group } & \multirow{3}{*}{$F(1,78)$} & \multirow{3}{*}{$\begin{array}{l}\text { Effect Size } \\
\left(\text { partial } \eta^{2}\right)\end{array}$} \\
\hline & Young & Old & & \\
\hline & $N=44$ & $N=36$ & & \\
\hline \multicolumn{5}{|c|}{ Valid voluntary memories $^{\mathrm{a}}$} \\
\hline Mean & 24.20 & 18.89 & $15.61 * *$ & 0.16 \\
\hline SD & 5.88 & 6.28 & & \\
\hline Range & $8-30$ & $5-30$ & & \\
\hline \multicolumn{5}{|c|}{ Valid recorded involuntary memories } \\
\hline Mean & 9.93 & 8.36 & 1.04 & 0.01 \\
\hline SD & 5.50 & 8.22 & & \\
\hline Range & $1-25$ & $1-38$ & & \\
\hline \multicolumn{5}{|c|}{ Ticked involuntary memories } \\
\hline Mean & 7.16 & 1.42 & $9.62 *$ & 0.11 \\
\hline $\mathrm{SD}$ & 10.91 & 2.21 & & \\
\hline Range & $0-44$ & $0-8$ & & \\
\hline \multicolumn{5}{|c|}{ Total involuntary memories (recorded plus ticked) } \\
\hline Mean & 17.16 & 9.78 & $7.99 *$ & 0.09 \\
\hline SD & 13.48 & 8.86 & & \\
\hline Range & $1-65$ & $1-40$ & & \\
\hline
\end{tabular}

$* p<.01 * * p<.001$

${ }^{\text {a }}$ Degrees of freedom for voluntary memories were $(1,80)$ as the data of all 38 older participants were included into the analysis. 
Table 4

Percentages (Frequencies) of Involuntary Memories as a Function of Age Group (Young vs. Old) and Type of Reported Trigger (External vs. Internal vs. None).

\begin{tabular}{lllll}
\hline & \multicolumn{3}{c}{ Type of Trigger } & \\
& External & Internal & None & Total \\
\hline Young & $52 \%(229)$ & $25 \%(107)$ & $23 \%(101)$ & $100 \%(437)$ \\
Old & $72 \%(216)$ & $20 \%(60)$ & $8 \%(25)$ & $100 \%(301)$ \\
Total & $60 \%(445)$ & $23 \%(167)$ & $17 \%(126)$ & $100 \%(738)$ \\
\hline
\end{tabular}


Table 5

Overall Mean Ratings (Standard Deviations) of Memory Characteristics as a Function of Memory Type (Involuntary vs. Voluntary) and Age Group (Young vs. Old).

\begin{tabular}{lllll}
\hline & \multicolumn{2}{l}{ Involuntary Memories } & \multicolumn{2}{l}{ Voluntary Memories } \\
\cline { 2 - 5 } & Old & Young & Old & Young \\
\hline Specificity $^{\mathrm{a}}$ & $0.75(0.20)$ & $0.80(0.14)$ & $0.51(0.11)$ & $0.67(0.12)$ \\
Rehearsal $^{\mathrm{b}}$ & $2.98(0.82)$ & $2.63(0.70)$ & $3.02(0.77)$ & $2.41(0.60)$ \\
Memory Pleasantness $^{\mathrm{b}}$ & $3.65(0.72)$ & $3.32(0.70)$ & $3.22(0.42)$ & $3.20(0.55)$ \\
Event Pleasantness $^{\mathrm{b}}$ & $3.59(0.82)$ & $3.21(0.79)$ & $3.06(0.46)$ & $3.12(0.29)$ \\
Unusualness $^{\mathrm{b}}$ & $3.86(0.79)$ & $3.44(0.66)$ & $3.57(0.51)$ & $3.47(0.47)$ \\
Vividness $^{\mathrm{c}}$ & & & & \\
Age of Memory $^{\mathrm{d}}$ & $3.48(1.23)$ & $4.91(0.83)$ & $5.48(.94)$ & $5.10(0.76)$ \\
\hline
\end{tabular}

Note $-{ }^{\text {a }}$ Memories were Rated as Specific or General. Means Represent Mean

Proportions of Specific Memories Averaged across Participants.

${ }^{\mathrm{b}}$ Ratings were Made on 5-Point Scales. For Rehearsal, Scale Points were 1=Never, 2=Once or Twice, 3=A Few Times, 4=Several Times, and 5=Many Times. For Memory and Event Pleasantness, Scale Points were $1=$ Very Unpleasant, $3=$ Neutral, and 5=Very Pleasant.For Unusualness, Scale Points were 1=Very Common, 5=Very Unusual.

${ }^{\mathrm{c}}$ Ratings were Made on a 7-Point Scale (1=Very Vague, Almost no Image at all; $7=$ Very Vivid, Almost Like Normal Vision).

${ }^{\mathrm{d}}$ For Each Memory, Age was Calculated by Subtracting Participants' Age in Memory from Their Current Chronological Age 
Figure Captions

Figure 1. Overall Mean Pleasantness Ratings as a Function of Memory Type

(Involuntary vs. Voluntary) and Age Group (Young vs. Old).

Figure 2. Numbers of Involuntary and Voluntary Memories in the Young Group as a Function of Retention Time (Expressed in Years +1 Year).

Figure 3. Numbers of Involuntary and Voluntary Memories in the Old Group as a Function of Retention Time (Expressed in Decades). 
Effects of age on involuntary and voluntary memory 46

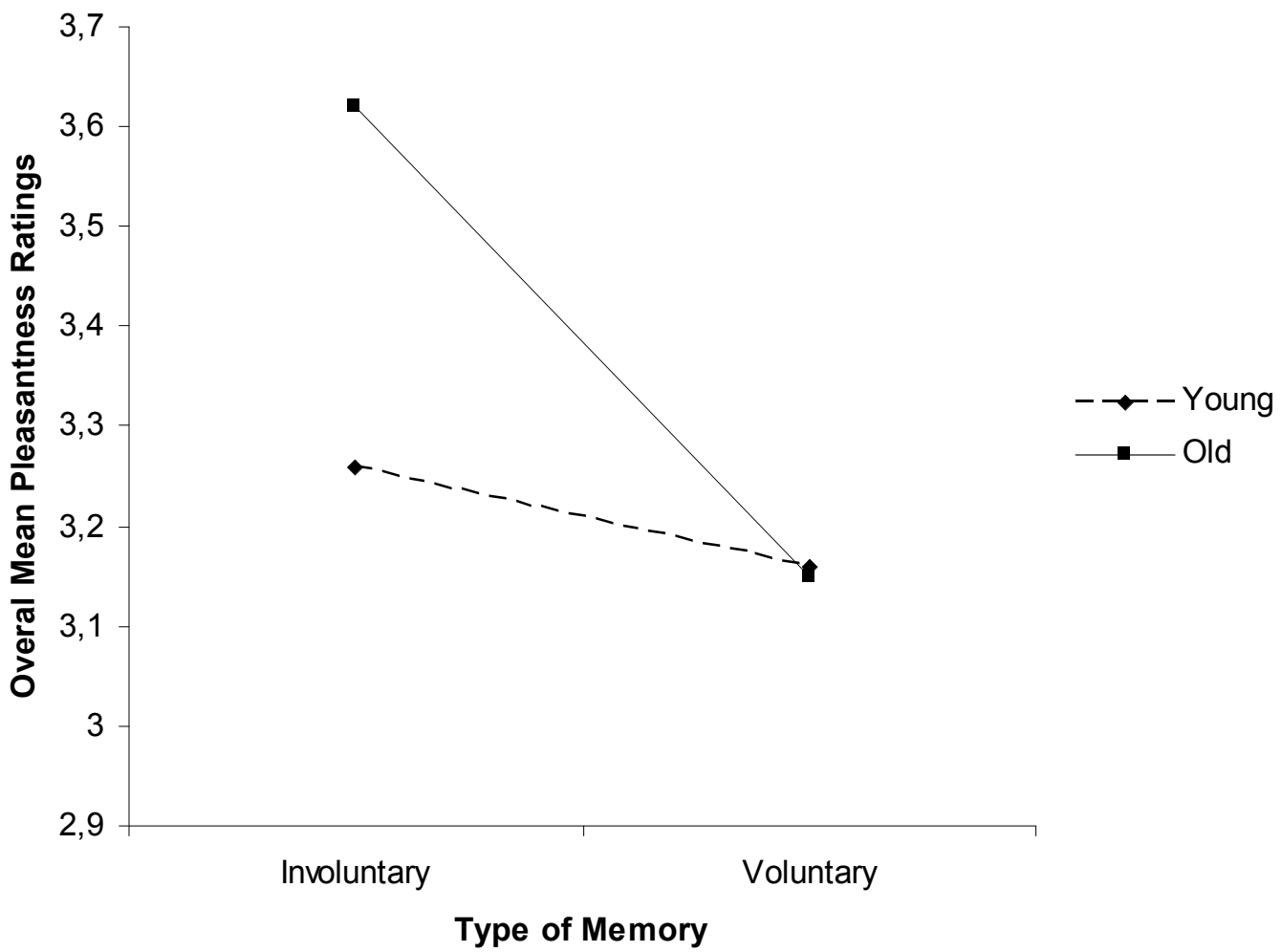

Figure 1 


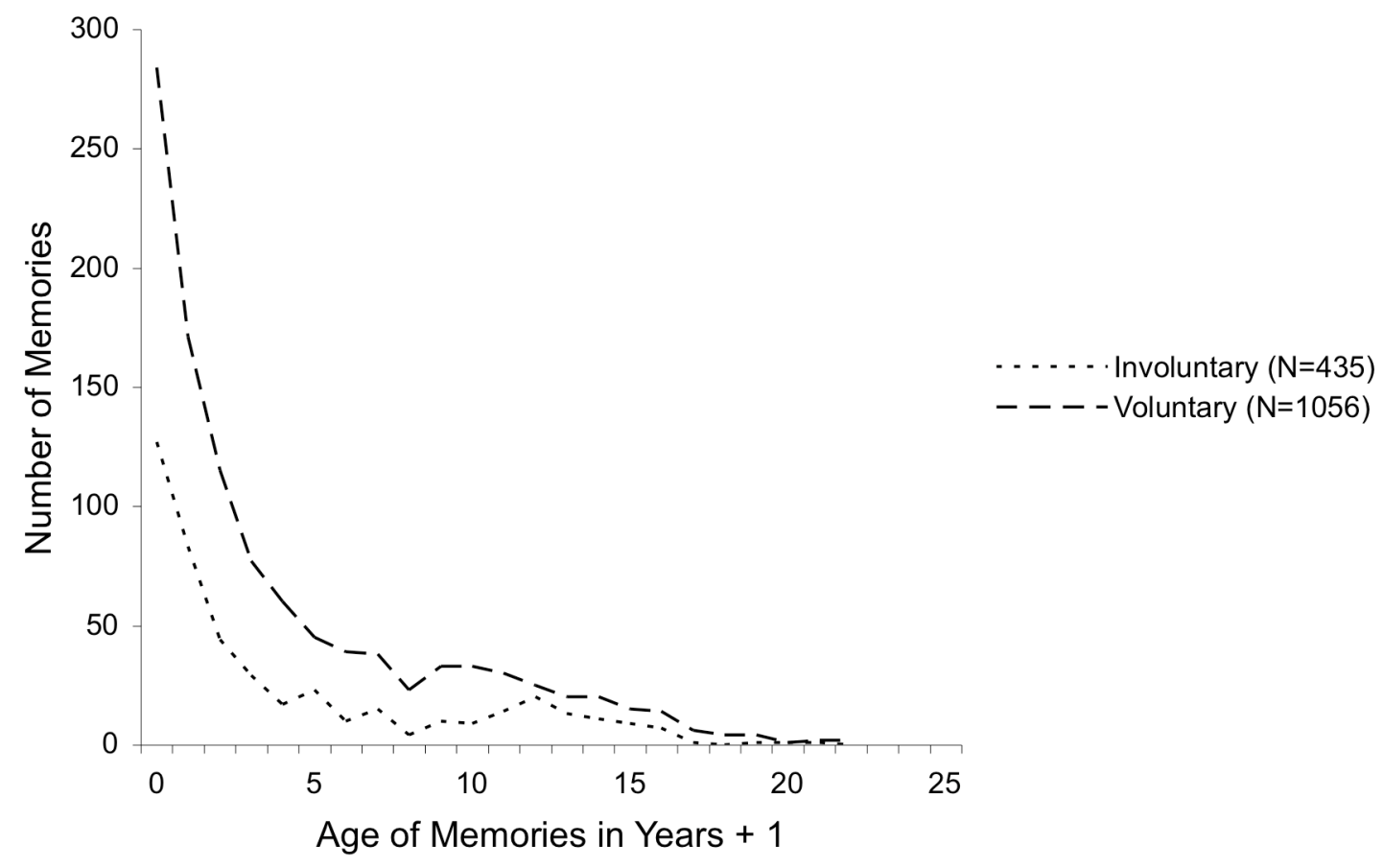

Figure 2 


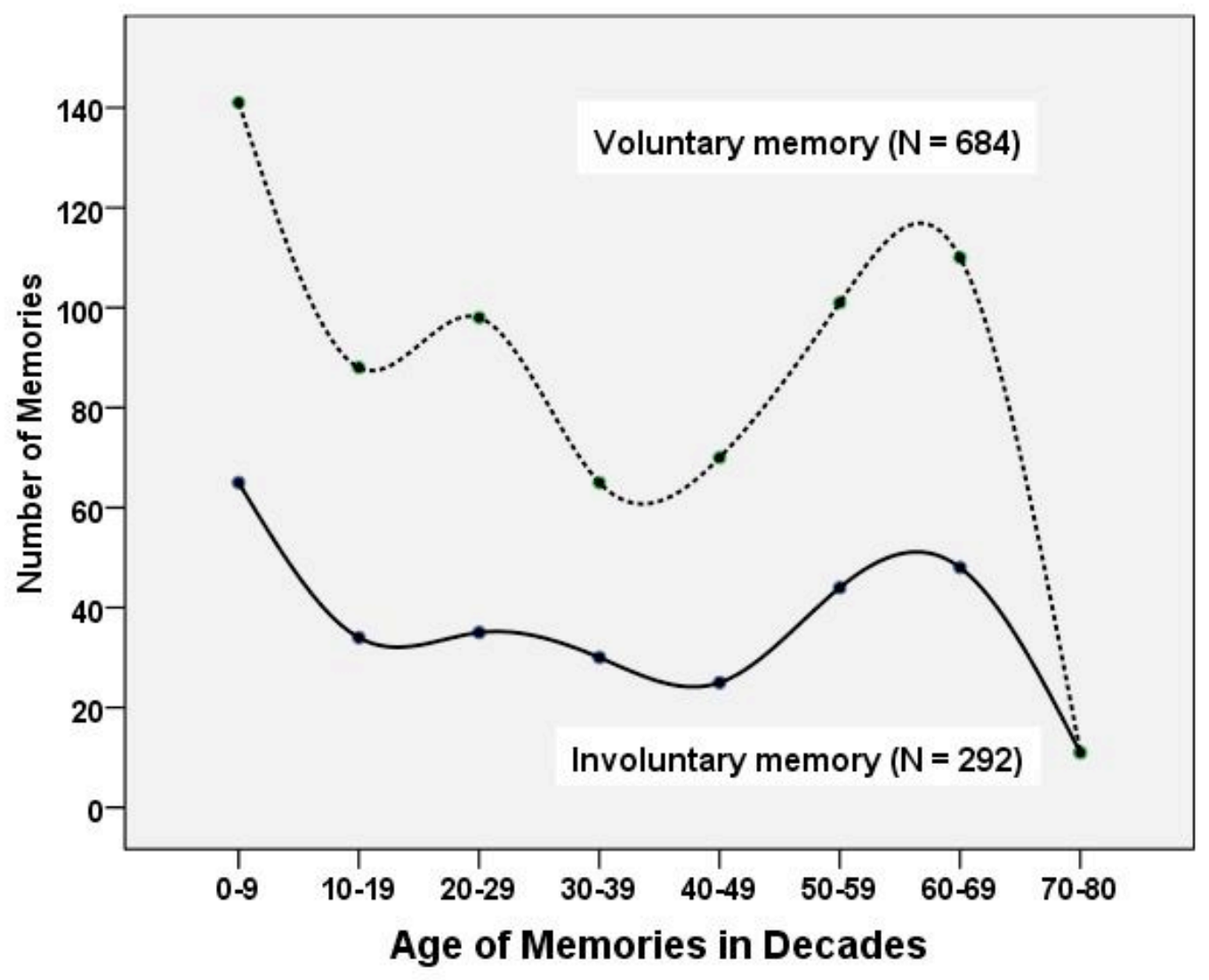

Figure 3 


\section{Appendix 1}

Instructions Received by Participants Concerning the Nature of Involuntary

Autobiographical Memories

An involuntary memory is a memory from your past that comes to you spontaneously all by itself i.e., without any deliberate attempt to retrieve it. In other words, a memory that simply 'pops' in to your mind. Involuntary memories can sometimes be triggered by something (either in your thoughts or in your environment) or they may occur without any apparent trigger. Involuntary memories may be of an event, situation or experience from your past.

Involuntary memories may vary in detail some may be specific and refer to a single episode that you experienced on a particular day (e.g., 'the day you moved into a new house' or 'how you passed your driving test'). Other memories may be more general and refer to events that lasted longer than one day. General memories can be of a single event that your experienced repeatedly over an extended period (i.e., 'visits to the dentist' or 'going to seaside every summer during your childhood') or they can be of an extended event that lasted for more than a day (for example, 'a trip to Paris') and the memory is of the whole trip, not a specific day. Involuntary memories can be many years old or only a few days (or hours) old. Furthermore, it may be that you have thought of the memory many times before or never before.

The important thing to remember is to only record involuntary memories - memories that 'pop' into your mind without you consciously trying to remember anything. 
Appendix 2

Written Instructions About How to Complete a Questionnaire for Each Recorded

Autobiographical Memory (Appended at the End of Diary)

You will find 14 questions in each questionnaire. Some are structured (you should mark by a circle around the appropriate response). Other questions are open (you describe something in your own words). Each of these 14 questions is explained in detail below:

1. Indicate the time and date that you experienced the memory.

2. Indicate the time and date when you recorded the memory.

3. Indicate by circling a number on the scale, what was your mood immediately before the memory came to mind. ' 1 ' indicates your mood was very negative, ' 5 ' indicates it was very positive, and ' 3 ' indicates neutral mood, i.e., you were neither happy nor unhappy.

4. Briefly describe the content of your memory i.e., what your memory is about. Below are three examples given in a previous study in America:

(a) 'I was remembering how embarrassed I was at 13 to wear open toed sandals and dresses".

(b) 'This sensation took me back to the summers when my sister and I would spend everyday in the swimming pool. We used to do tricks and often water would go up our noses. We were about 7 and 8 respectively when we were allowed to be out there alone'.

(c) 'Seven years ago I was driving home in the rain to visit my parents in San Diego. Very heavy rain and the defrost didn't work on my 66 Mustang which I drove at the time'.

5. Evaluate how vivid your memory is i.e., how clear is the image in your mind. Do you have a very vivid image which is almost like normal vision or is the image very vague with almost no image at all? ' 1 ' indicates you had a very vague image in your mind, almost no image at all and ' 7 ' indicates you have a very vivid image in your mind, almost like normal vision.

6. Indicate (by circling the relevant option) whether or not there was something that triggered the memory. This might be something in your environment or something in your thoughts. For example remembering "driving home in rain to visit my parents in San Diego" was triggered by "heavy rain on freeway"”. Remembering "how embarrassed I was at 13 to wear open toed sandals" " was triggered by the sight of the" older lady's open toed sandals". Memories can be triggered by just about anything or sometimes by nothing at all, if there was no trigger circle (c) and move onto question 7.

7. If there was a trigger, describe what it was that triggered your memory.

8. Indicate by circling a number on the scale, to what extent you were concentrating on the activity when the memory came to mind. ' 1 ' indicates you were not concentrating at all on the activity, ' 5 ' indicates you were fully concentrating and ' 3 ' indicates a medium level of concentration.

9. Evaluate whether your memory is about an unusual or common event/experience in your life. That is, is it a unique and surprising event or an everyday event and like many others. ' 1 ' indicates a very common event and 
' 5 ' indicates the event/experience was very unusual. ' 3 ' indicated the event was neither common nor unusual.

10. Evaluate how pleasant or unpleasant your memory is. Is it positive and pleasant to remember or is it negative and unpleasant to remember.

Circling a ' 3 ' indicates your memory is neutral i.e., neither pleasant nor unpleasant.

11. Evaluate how pleasant or unpleasant the original event was at the time you experienced it, i.e., was the event that you remembered positive and pleasant or negative and unpleasant at the time you experienced it in your life. Circling a ' 3 ' indicates that the event at the time you experienced it was neutral i.e., neither pleasant nor unpleasant.

12. Indicate whether the memory is of a specific or general event/experience. A specific event refers to a single episode in your life (e.g., the day you moved into your new house or the day a family member was born). A general event may refer to an extended event (e.g., a trip to Paris) or a single event that occurred repeatedly over an extended period (e.g., travelling on the tube every morning when working in the City; going to seaside every summer during your childhood).

13. Write in years your age at that time (i.e., when the memory originally took place). If you do not remember how old you were state an estimated age, e.g., 15-17 years.

14. Indicate (by circling the relevant number) whether you have had this memory before. It does not matter if memory has come to mind involuntarily before, or that you have deliberately recalled the memory before - just indicate how often you have remembered the event/situation. 
Appendix 3

A List of 30 Word Cues Used in Session 2 for Voluntary Autobiographical Memories

1. Warm fire (positive)

2. Ugly face (negative)

3. Phone box (neutral)

4. Friendly host (positive)

5. Feeling safe (positive)

6. Toothache (negative)

7. Lunch box (neutral)

8. Good genes (positive)

9. Terrible singing (negative)

10. Uncomfortable bed (negative)

11. Lucky find (positive)

12. Broken promise (negative)

13. Cleaning products (neutral)

14. Handwriting (neutral)

15. Seeing the sunset (positive)

16. Special place (positive)

17. Answering the telephone (neutral)

18. Giving directions (neutral)

19. Having a row (negative)

20. Pile of papers (neutral)

21. Tape recorder (neutral)

22. First date (positive)

23. Saying goodbye (negative)

24. Stressful day (negative)

25 . Knocking on a door (neutral)

26. Sight seeing (positive)

27. Back pain (negative)

28. Being shouted at (negative)

29. Corner shop (neutral)

30. Feeling proud (positive) 


\section{Author Note}

Simone Schlagman, School of Psychology, University of Hertfordshire, UK.

S.S. is now at Inter-Research Science Center, Oldendorf/Luhe, Germany.

Matthias Kliegel, Department of Psychology, Technische Universität Dresden, Germany.

Jörg Schulz, School of Psychology, University of Hertfordshire, UK.

Lia Kvavilashvili, School of Psychology, University of Hertfordshire, UK.

The research presented in this paper was supported by a doctoral studentship awarded to Simone Schlagman from the Economic and Social Research Council, UK, and a senior research fellowship awarded to Lia Kvavilashvili from the British Academy/Leverhulme Trust, UK. We are grateful to anonymous reviewers for their helpful comments and suggestions on earlier drafts of the paper.

Correspondence concerning this article should be addressed to Lia Kvavilashvili, School of Psychology, University of Hertfordshire, College Lane, Hatfield, Herts, AL10 9AB, UK. Email: L.Kvavilashvili@herts.ac.uk 